\title{
Cyclopentenone and Furan Derivative from the Mycelia of Cordyceps cicadae
}

\author{
Shu-Wei Zhang, Li-Jiang Xuan
}

Received: October 24, 2007 / Accepted: January 16, 2008

(C) Japan Antibiotics Research Association

\begin{abstract}
A new cyclopentenone derivative, named as 2(3-carboxy-2-hydroxypropyl)-3-methyl-2-cyclopentenone, and a new furan derivative, named as 5-(2-hydroxyethyl)-2furanacetic acid, were isolated from the cultivated Cordyceps cicadae mycelia. Their structures were determined by spectroscopic methods, including 2D NMR analyses.
\end{abstract}

Keywords cyclopentenone derivative, furan derivative, structure elucidation, Cordyceps cicadae

Cordyceps cicadae, belonging to the genus Cordyceps (family Clavicipitaceae, Ascomycotina), is a major parasitic fungus growing on the larvae of Cicada flammata, Platypleura kaempferi, Crytotympana pustulata, or Platylomia pieli. Some bioactive contents, for example, polysaccharides [1], galactomannan [2], cordycepin, adenosine [3], and ISP-1 (myriocin) [4] have been isolated from Cordyceps cicadae. Because the natural resource of Cordyceps cicadae is very scarce, it is important to research on the cultivation of fungi, pharmacological function and chemical contents of the cultivated mycelia of Cordyceps cicadae. Chen [5] found that Paecilomyces cicadae could grow on the wheat culture medium well and the cultivated mycelia show the same pharmacological function as the natural fungi. Jin [6] found that the cultivated mycelia of Cordyceps cicadae could prevent the progression of chronic renal failure (CRF) in the rat

L.-J. Xuan (Corresponding author), S.-W. Zhang: Shanghai Institute of Materia Medica, Chinese Academy of Science, $555 \mathrm{Zu}$ Chong Zhi Road, Shanghai 201203, P. R. China,

E-mail: ljxuan@mail.shcnc.ac.cn glomerulosclerosis model.

In order to investigate the chemical contents of cultivated mycelia of Cordyceps cicadae, we isolated the extract of $70 \%$ aqueous ethanol. In the preceding paper, we have reported five new aromatic 4-O-methylglucosides from the cultivated mycelia of Cordyceps cicadae [7]. In this paper, we report the isolation and structure elucidation of a new cyclopentenone derivative and a new furan derivative, from the cultivated Cordyceps cicadae mycelia. They were characterized as 2-(3-carboxy-2-hydroxypropyl)-3-methyl2-cyclopentenone (1) and 5-(2-hydroxyethyl)-2-furanacetic acid (2), respectively, by spectroscopic methods.

The method of the cultivation of fungi was described in the preceding paper $[5,7]$.

The cultivated mycelia of Cordyceps cicadae (4.0 kg) were extracted three times with 24 liters $70 \%$ (v/v) aqueous $\mathrm{EtOH}$ at room temperature. The combined extracts were concentrated to give deep-brown syrup. Then, the syrup was suspended in water and extracted with $\mathrm{CHCl}_{3}$ and $\mathrm{BuOH}$ orderly. The aqueous fraction after extraction by $\mathrm{CHCl}_{3}$ and $\mathrm{BuOH}$ was concentrated to one liter. Then, this aqueous solution was subjected to column chromatography packed with $\mathrm{MCI}$ gel and eluted with $\mathrm{MeOH}: \mathrm{H}_{2} \mathrm{O}$ $(0: 1 \sim 4: 6$, step gradient) collecting $50 \mathrm{ml}$ fractions to give Fractions B1 B5. Fraction B2 (eluted by $2: 8 \mathrm{MeOH}-$ $\mathrm{H}_{2} \mathrm{O}$ ) was rechromatoraphed by column over MCI gel and eluted with $20 \%$ aqueous methanol collecting $10 \mathrm{ml}$ fractions. Fractions $28 \sim 43$ afforded partially pure 1 and fractions $49 \sim 60$ afforded partially pure 2 . Final purification was performed by HW-40F column chromatography eluted with $\mathrm{H}_{2} \mathrm{O}$ to provide purified samples of $\mathbf{1}(15 \mathrm{mg})$ and $\mathbf{2}$ (8.0 mg).

1 was obtained as light-yellow gum. It was shown to have a molecular formula $\mathrm{C}_{10} \mathrm{H}_{14} \mathrm{O}_{4}$ by HR-ESI-MS $(\mathrm{m} / \mathrm{z}$ 221.0794, $[\mathrm{M}+\mathrm{Na}]^{+}$, calcd 221.0790), which was consistent with ${ }^{1} \mathrm{H}$ - and ${ }^{13} \mathrm{C}-\mathrm{NMR}$ spectra and DEPT 
Table 1 NMR spectral data for 2-(3-carboxy-2hydroxypropyl)-3-methyl-2-cyclopentenone (1) in $\mathrm{D}_{2} \mathrm{O}^{\mathrm{a}}$

\begin{tabular}{rrrl}
\hline No. & ${ }^{1} \mathrm{H}(\delta)$ & ${ }^{13} \mathrm{C}(\delta)$ & \multicolumn{1}{c}{$\mathrm{HMBC}$} \\
\hline 1 & & $217.8 ; \mathrm{s}$ & \\
2 & & $137.9 ; \mathrm{s}$ & \\
3 & & $183.6 ; \mathrm{s}$ & \\
4 & $2.66 ; 2 \mathrm{H}, \mathrm{m}$ & $34.6 ; \mathrm{t}$ & $\mathrm{C}-1, \mathrm{C}-2, \mathrm{C}-3, \mathrm{C}-5$ \\
5 & $2.45 ; 2 \mathrm{H}, \mathrm{m}$ & $36.9 ; \mathrm{t}$ & $\mathrm{C}-1, \mathrm{C}-2, \mathrm{C}-3, \mathrm{C}-4$ \\
6 & $2.43 ; 2 \mathrm{H}, \mathrm{m}$ & $32.7 ; \mathrm{t}$ & $\mathrm{C}-1, \mathrm{C}-2, \mathrm{C}-3, \mathrm{C}-7, \mathrm{C}-8$ \\
7 & $4.19 ; 1 \mathrm{H}, \mathrm{m}$ & $69.6 ; \mathrm{d}$ & $\mathrm{C}-2, \mathrm{C}-6, \mathrm{C}-8, \mathrm{C}-9$ \\
8 & $2.55 ; 1 \mathrm{H}, \mathrm{dd}$, & $43.8 ; \mathrm{t}$ & $\mathrm{C}-6, \mathrm{C}-7, \mathrm{C}-9$ \\
& $\mathrm{~J}=4.8,15.6$ & & \\
& $2.48 ; 1 \mathrm{H}, \mathrm{dd}$, & & \\
9 & $\mathrm{~J}=8.2,15.5$ & & \\
10 & $2.18 ; 3 \mathrm{H}, \mathrm{s}$ & $19.9 ; \mathrm{q}$ & $\mathrm{C}-2, \mathrm{C}-3, \mathrm{C}-4$ \\
\hline
\end{tabular}

${ }^{a}$ Recorded on a Varian mercury NMR spectrometer at $400 \mathrm{MHz}$ for ${ }^{1} \mathrm{H}$ and $100 \mathrm{MHz}$ for ${ }^{13} \mathrm{C}$. $\delta$ in ppm; $J$ in $\mathrm{Hz}$. The multiplicities of the carbon signals were determined indirectly from $\mathrm{HMOC}$ experiments.

experiment. The IR spectrum revealed the presence of $\mathrm{OH}$ $\left(3411 \mathrm{~cm}^{-1}\right)$, carboxyl $\left(\sim 1720 \mathrm{~cm}^{-1}\right.$, shoulder, overlapped with carbonyl absorption band at $\left.1697 \mathrm{~cm}^{-1}\right), \alpha, \beta$ unsaturated carbonyl $\left(1697 \mathrm{~cm}^{-1}\right.$, brs and $\left.1635 \mathrm{~cm}^{-1}\right)$, whereas the UV spectrum showed an absorption maximum at $236 \mathrm{~nm}(\varepsilon 8395)$, which was suggestive of the presence of an enone.

${ }^{1} \mathrm{H}-\mathrm{NMR}$ spectrum showed 13 proton signals and ${ }^{13} \mathrm{C}$ NMR spectrum showed 10 carbon signals (Table 1). The 10 carbons were characterized by DEPT-135 spectrum as one methyl, four methylenes, one methine, two olefinic quarternary carbon, one carbonyl carbon, and one carboxyl carbon (Table 1).

The COSY experiment on $\mathbf{1}$ indicated the presence of a common partial structure shown as bold lines in Fig. 1, whereas the connectivities of the quaternary carbons were elucidated by an HMBC experiment. The HMBC correlations from $\mathrm{H}-4$ to $\mathrm{C}-1$ and $\mathrm{C}-3$, from $\mathrm{H}-5$ to $\mathrm{C}-1$, and from $\mathrm{H}-\mathrm{CH}_{3}$ to $\mathrm{C}-2, \mathrm{C}-3$ and $\mathrm{C}-4$ indicated the fragment of 3-methylcyclopent-2-enone. The HMBC correlations from H-7 and H-8 to the carboxyl carbon indicated the carboxyl group was connected to $\mathrm{C}-8(\delta$ 43.8). The HMBC correlations from $\mathrm{H}-6$ to $\mathrm{C}-1(\delta 217.8), \mathrm{C}-2(\delta 137.9)$ and C-3 $(\delta$ 183.6) and from $\mathrm{H}-7$ to $\mathrm{C}-2(\delta$ 137.9) indicated that the $\mathrm{C}-6$ atom was connected to $\mathrm{C}-2$.

On the basis of these evidences, the structure of 1 were elucidated as 2-(3-carboxy-2-hydroxypropyl)-3-methyl-2cyclopentenone (Fig. 1).

2 was isolated as light-yellow powder. HR-ESI-MS
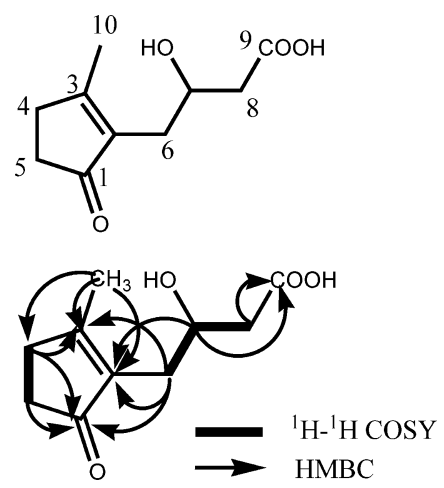

Fig. 1 The COSY and key HMBC correlations of 2-(3carboxy-2-hydroxypropyl)-3-methyl-2-cyclopentenone (1).

Table 2 NMR spectral data for 5-(2-hydroxyethyl)-2furanacetic acid (2) in $\mathrm{CD}_{3} \mathrm{OD}^{\mathrm{a}}$

\begin{tabular}{crll}
\hline No. & \multicolumn{1}{c}{${ }^{1} \mathrm{H}(\delta)$} & ${ }^{13} \mathrm{C}(\delta)$ & \multicolumn{1}{c}{$\mathrm{HMBC}$} \\
\hline 1 & & $175.5 ; \mathrm{s}$ & \\
2 & $3.61 ; 2 \mathrm{H}, \mathrm{s}$ & $35.6 ; \mathrm{t}$ & $\mathrm{C}-1, \mathrm{C}-3, \mathrm{C}-4$ \\
3 & & $148.8 ; \mathrm{s}$ & \\
4 & $6.12 ; 1 \mathrm{H}, \mathrm{d}, \mathrm{J}=3.12$ & $110.1 ; \mathrm{d}$ & $\mathrm{C}-3, \mathrm{C}-5, \mathrm{C}-6$ \\
5 & $6.06 ; 1 \mathrm{H}, \mathrm{d}, \mathrm{J}=3.1$ & $108.6 ; \mathrm{d}$ & $\mathrm{C}-3, \mathrm{C}-4, \mathrm{C}-6$ \\
6 & & $154.2 ; \mathrm{s}$ & \\
7 & $2.80 ; 2 \mathrm{H}, \mathrm{t}, \mathrm{J}=6.7$ & $32.6 ; \mathrm{t}$ & $\mathrm{C}-5, \mathrm{C}-6, \mathrm{C}-8$ \\
8 & $3.77 ; 2 \mathrm{H}, \mathrm{t}, \mathrm{J}=6.7$ & $61.6 ; \mathrm{t}$ & $\mathrm{C}-7, \mathrm{C}-6$ \\
\hline
\end{tabular}

${ }^{a}$ Recorded on a Varian mercury NMR spectrometer at $400 \mathrm{MHz}$ for ${ }^{1} \mathrm{H}$ and $100 \mathrm{MHz}$ for ${ }^{13} \mathrm{C}$. $\delta$ in ppm; $J$ in $\mathrm{Hz}$. The multiplicities of the carbon signals were determined indirectly from $\mathrm{HMOC}$ experiments.

analysis revealed the molecular of 2 was $\mathrm{C}_{8} \mathrm{H}_{10} \mathrm{O}_{4}(\mathrm{~m} / \mathrm{z}$ 193.0479, $[\mathrm{M}+\mathrm{Na}]^{+}$, calcd 193.0477). The IR spectrum showed the presence of hydroxyl $\left(3427 \mathrm{~cm}^{-1}\right)$, carboxyl $\left(1712 \mathrm{~cm}^{-1}\right)$ and olefinic $\left(1635 \mathrm{~cm}^{-1}\right)$ absorption bands.

The ${ }^{1} \mathrm{H}-\mathrm{NMR}$ spectrum showed eight proton signals, including an olefinic $-\mathrm{CHCH}-$ coupling system $[\delta 6.06$ $(1 \mathrm{H}, \mathrm{d}, J=3.1 \mathrm{~Hz}, 5-\mathrm{H})$ and $\delta 6.12(1 \mathrm{H}, \mathrm{d}, J=3.1 \mathrm{~Hz}, 4-\mathrm{H})]$, a $-\mathrm{CH}_{2} \mathrm{CH}_{2}-$ coupling system $[\delta 3.77(2 \mathrm{H}, \mathrm{t}, J=6.7 \mathrm{~Hz}, 8$ $\mathrm{H})$ and $2.80(2 \mathrm{H}, \mathrm{t}, J=6.7,7-\mathrm{H})]$, and a singlet signal at $\delta$ $3.61(2 \mathrm{H}, \mathrm{s}, 2-\mathrm{H})$ (Table 2). The ${ }^{13} \mathrm{C}-\mathrm{NMR}$ and DEPT-135 spectra showed eight carbon signals, characterized as a $\mathrm{COOH}$, two oxygenated quaternary $s p^{2}$ carbon atoms, two $s p^{2}$ methines, and three $s p^{3}$ methylenes (Table 2). The ${ }^{13} \mathrm{C}$ NMR shifts of olefinic carbons $[\delta 148.8$ (C-3), 110.1 (C-4), 108.6 (C-5), 154.2 (C-6)] and the coupling constant of two olefinic protons $(J=3.1 \mathrm{~Hz})$ indicated the present of furan ring.

The COSY experiment on $\mathbf{2}$ indicated the presence of two partial structures $\left(=\mathrm{CH}-\mathrm{CH}=\right.$ and $\left.-\mathrm{CH}_{2} \mathrm{CH}_{2}-\right)$ shown 

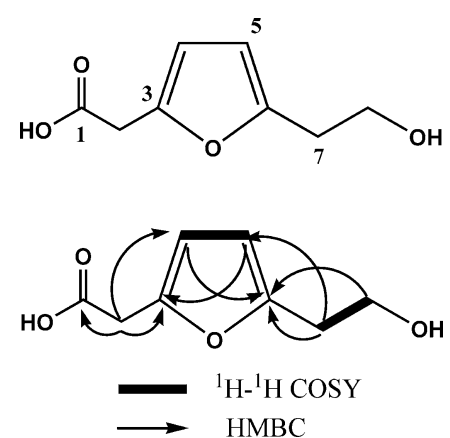

Fig. 2 The COSY and key HMBC correlations of 5-(2hydroxyethyll-2-furanacetic acid (2).

as bold lines in Fig. 2. The HMBC experiment showed the singlet protons at $\delta 3.61$ were correlated to the carboxyl carbon at $\delta 175.5$ and two olefinic carbons at $\delta 148.8$ and $\delta 110.1$, and the triplet protons at $\delta 2.80(2 \mathrm{H}, \mathrm{t}, J=6.7 \mathrm{~Hz}$, 7 -H) were correlated to two olefinic carbons at $\delta 154.2$ and $\delta$ 108.6. Other HMBC correlations were shown in Fig. 2 and Table 2.

Thus, 2 were characterized as 5-(2-hydroxyethyl)-2furanacetic acid.

Acknowledgement The authors are grateful to Dr. Zhu-An Chen for identification and cultivation of the fungi.

\section{References}

1. Kiho T, Ito M, Nagai K, Hara C, Ukai S. Polysaccharides in fungi. X XII. a water soluble polysaccharide from the alkaline extract of the insect-body portion of Chan hua (fungus: Cordyceps cicadae). Chem Pharm Bull 36: 3032-3037 (1988)

2. Ukai S, Matsuura S, Hara C, Kiho T, Hirose K. Structure of a new galactomannan from the ascocarps of Cordyceps cicadae shing. Carbohydr Res 101: 109-116 (1982)

3. Furuya T, Hirotani M, Matsuzawa M. $N^{6}-(2-$ Hydroxyethyl)adenosine, a biologically active compound from cultured mycelia of Cordyceps and Isaria species. Phytochemistry 22: 2509-2512 (1983)

4. Fujita $\mathrm{T}$, Inoue $\mathrm{K}$, Yamamoto $\mathrm{S}$, Ikumoto $\mathrm{T}$, Sasaki $\mathrm{S}$, Toyama R, Chiba K, Hoshino Y, Okumoto T. Fungal metabolites, Part II, a potent immunosuppressive activity found in Isaria sinclairii metabolite. J Antibiot 47: 208-215 (1994)

5. Chen ZA, Liu GY, Hu SY. Studies on cultivation of Paecilomyces cicadae and its pharmacological function. Acta Mycologica Sinica 12: 138-144 (1993)

6. Jin ZH, Chen YP, Deng YY. The mechanism study of Cordyceps sobolifera mycelium preventing the progression of glomerulosclerosis. Chin J Integ Tradit West Nephrol 6: 132-136 (2005)

7. Zhang SW, Xuan LJ. Five aromatics bearing a 4-Omethylglucose unit from Cordyceps cicadae. Helvetica Chimica Acta 90: 404-410 (2007) 